\title{
O PLANO NACIONAL DE EDUCAÇÃO E AS TECNOLOGIAS DA INFORMAÇÃO E COMUNICAÇÃO
}

\author{
Antonio A. S. Zuin
}

\begin{abstract}
RESUMO: A tecnologia ocupa cada vez mais posição-chave na sociedade atual, de modo que ela não mais pode ser definida como uma somatória de novas técnicas operacionais, mas sim como um modus vivendi, como um processo social que determina as configuraçōes identitárias dos indivíduos e as do processo educacional/formativo. Dentro desse contexto, os autores desse artigo têm como objetivo refletir sobre o modo como as tecnologias de informação e comunicação, as denominadas TIC, foram consideradas no Documento Final da Conferência Nacional de Educação (CONAE), cujos apontamentos servirão de base para a elaboração das diretrizes e estratégias de ação do novo Plano Nacional da Educação (PNE) 2011-2020.
\end{abstract}

Palavras-chave: Tecnologia. Plano Nacional de Educação. Educação a distância. TIC. CONAE.

\section{THE NATIONAL PLAN FOR EDUCATION AND THE INFORMATION AND COMMUNICATION TECHNOLOGIES}

ABSTRACT: Technology holds an increasingly essential position in today's society: it can no longer be defined as the sum of new operational techniques. It has become a modus vivendi, a social process that determines both the identity configurations of individuals and the educational process. In this context, the authors reflect on the way

Pós-doutor em Filosofia da Educação e professor-associado do Departamento de Educação e do Programa de Pós-Graduação em Educação da Universidade Federal de São Carlos (UFSCAR).E-mail: dazu@ufscar.br

Agradeço as pertinentes contribuiçôes de Ivany Rodrigues Pino, as quais foram incorporadas no transcorrer do texto. 
information and communication technologies, the so called ICT, were treated in the final resolution of the National Conference of Education whose notes will serve as a basis to elaborate the guidelines and action strategies of the new 2011-2020 National Plan for Education.

Key words: Technology. National Plan for Education. Distance education. ICT. CONAE.

\section{Introdução}

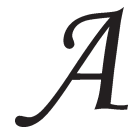

$s$ inovações tecnológicas, que despontam no mundo globalizado da mídia eletrônica, estão implicando em conformações diferenciadas da vida social contemporânea e levando a ressignificações de conceitos, tais como o de infância, juventude, velhice, família, inclusão ou exclusão social e muitos outros, pois remodelam sociedades e identidades em todo o mundo. Nos casos da infância e da juventude, Postman (2005) afirma o desaparecimento da infância em decorrência do fato de que, com a televisão, as informações são tão publicizadas que se tornam diluídas as linhas fronteiriças entre as crianças e os adultos. $\mathrm{Na}$ sociedade balizada na difusão irrestrita e avassaladora de informaçôes, o processo de alfabetização perderia sua característica de metáfora do desenvolvimento humano, pois as crianças, precocemente expostas à torrente de informações, não seriam capazes de elaborá-las, o que causaria uma espécie de descompasso entre a assimilação de tais informações e os estágios do desenvolvimento psicocognitivo infantil.

Assim, o acesso praticamente irrestrito às informaçôes engendraria tanto o desaparecimento da concepção moderna de infância - posto que não haveria mais segredos capazes de impulsionar as crianças a terem certas aptidões que as habilitariam, na fase adulta, a dominá-los -, quanto o surgimento do chamado adulto-criança, um ser híbrido situado entre os recém-nascidos e os senis, cujas destrezas que o identificariam como adulto estariam em franco declínio, tais como uma "refinada capacidade de pensar conceitualmente e em sequência a tolerância para com o adiamento da satisfação e uma preocupação com a continuidade histórica" (Postman, 2005, p. 113). Já Castells (2007) chega a afirmar que as vidas das pessoas estão sendo moldadas pelas forças das sociedades em rede, sob o impacto da globalização nas identidades, quando as interconexões 
entre a tecnologia, a economia e a cultura estão desafiando, combatendo e impactando umas às outras em escala mundial.

Nesse novo contexto, ocorrem processos sociais profundos, gerando outros tipos de desigualdades, que vêm se agregar às existentes, de modo que mais diferenças sociais e econômicas são deixadas a descoberto, de forma contrastante, e iluminam novas formas de poder e controle social em uma sociedade de classes fortemente marcada pela marginalização das pessoas. Uma das contradições marcantes é a de que, ao mesmo tempo em que as forças impactantes caminham no sentido do reforço do poder e controle social, elas podem permitir dimensões democráticas, na medida em que as novas tecnologias de mídia, distribuídas com acesso livre e diversificadas, permitem mais fluidez e maior participação social. Evidentemente, as políticas educacionais desenvolvidas em nosso país não podem ser apartadas, ou mesmo se apartarem, do enfrentamento de tal contradição, ou seja, o uso das chamadas novas tecnologias de informação e comunicação (TIC) pode enveredar tanto para o recrudescimento do poder e controle social, quanto para o reforço de práticas democráticas.

De todo modo, diante de tantas transformações presentes nas esferas privada e pública envolvidas na utilização das TIC, os indivíduos precisam pensar criticamente o presente, colocando-lhe questôes e procurando caminhos possíveis de apreensões, interpretações e entendimentos, enfim, maior compreensão, no sentido de se construir trajetórias progressistas face às transformações em curso. Partindo do reconhecimento da necessidade e da importância desse exercício crítico de pensamento, os autores desse artigo têm como objetivo refletir sobre o modo como as TIC foram consideradas no Documento Final da Conferência Nacional de Educação (CONAE), cujas consideraçôes servirão de base para a elaboração das diretrizes e estratégias de ação do novo Plano Nacional da Educação (PNE) 2011-2020.

\section{A CONAE, o PNE e as TIC}

Na leitura do Documento-Referência da CONAE, notadamente no que diz respeito à relação entre o Sistema Nacional de Educação (SNE) e as TIC, nota-se, entre os vários escopos do SNE, o incentivo à presença de práticas educacionais que promovam o desenvolvimento de "tecnologias 
educacionais e recursos pedagógicos apropriados ao processo de aprendizagem, laboratórios de informática, pesquisa on-line e intercâmbio científico e tecnológico, nacional e internacional, entre instituiçóes de ensino, pesquisa e extensão" (CONAE, 2010, p. 32-33).

É interessante observar que tais objetivos do SNE, quanto à relação entre tecnologia, informação e comunicação, se refiram aos aspectos técnicos, pois há certa ausência no Documento-Referência da CONAE a respeito das ressignificaçôes que as inovações tecnológicas determinam na infância, na inclusão e exclusão social e nos processos educacional/ formativo. Não se pode asseverar que há uma ausência total de considerações sobre as TIC naquele documento. Como exemplo, a polêmica sobre a educação a distância é mencionada e será analisada nesse artigo, mas não há como se tornar indiferente ao modo como as influências das TIC são superficialmente mencionadas e refletidas no texto daquele documento, principalmente se compararmos tal superficialidade com as várias páginas, cujos conteúdos objetivam pertinentes reflexões sobre temáticas tais como qualidade da educação, financiamento da educação, e a relação entre a educação e processos de inclusão, diversidade e igualdade. Nesse momento, surgem as questões: 1) Quais seriam as razões da temática das novas tecnologias de informação e comunicação ser tratada de forma periférica, sobretudo num documento de tal importância, uma vez que se propõe a subsidiar a elaboração das diretrizes de ação do PNE 2011-2020 e do SNE?; 2) Se as inovações tecnológicas acarretam tantas ressignificações em nossas vidas e, particularmente, na construção de nossas identidades como educadores, por que tal preocupação não adquiriu a condição de eixo temático no Documento-Referência da CONAE?

Talvez, as respostas para essas questões se refiram ao fato de que tais transformações proporcionadas pelo desenvolvimento das forças produtivas, notadamente as de âmbito tecnológico, ocorrem numa tal velocidade que dificultam a composição de reflexões mais elaboradas sobre tal processo. Provavelmente, diante da rapidez do desenvolvimento dessas tecnologias, a expressão, tão comumente usada, de que estamos dentro do "olho do furacão", não represente apenas uma figura de linguagem. Se, na época do incipiente capitalismo monopolista, era verossímil a ponderação materialista-histórica de Walter Benjamin (1985) de que a superestrutura se modifica mais lentamente do que suas bases econômicas, então, talvez até mesmo Benjamin se assombrasse diante da 
velocidade que as atuais relaçôes de produção impingem à esfera da superestrutura, as quais precisam acompanhar o ritmo cada vez mais acelerado de tais mudanças. Se, por exemplo, na sociedade atual, alguém não se apresenta por meio de uma identidade eletrônica, é como se essa pessoa não existisse fisicamente; como se a sua existência concreta necessitasse ser virtualmente confirmada, pois, caso contrário, não seria percebida pelos outros. É nessa atual sociedade que o computador há muito deixou de ser um aparelho caracterizado como uma máquina de escrever aperfeiçoada, pois essa máquina

(...) já não tende apenas a ser um instrumento geral de trabalho, mas também a representar o entroncamento técnico, o ponto de encontro social, e o nevrálgico individual, em que processamento e transmissão de dados, televisão e telecomunicação, trabalho e atividade de tempo livre, concentração e distração, ser "bacana" e "por fora", observado e ignorado se misturam até a indiferenciação. Baixar dados, enviá-los e recebê-los passam a significar a atividade por excelência. A compulsão à ocupação é especificada em uma compulsão à emissão. Ela transforma-se, entretanto, em uma forma vital de expressão. Emitir quer dizer tornar-se percebido: ser. Não emitir é equivalente a não ser - não apenas sentir o horror vacui da ociosidade, mas ser tomado da sensação de simplesmente não existir. Não mais apenas: "há um vácuo em mim", porém "sou um vácuo" - de forma alguma "aí". (Türcke, 2002, p. 43)

Esse sentimento de vacuidade, que é "elaborado" pela compulsão contínua de emitir eletronicamente dados da própria vida, torna-se a atividade por excelência não tanto por conta do exercício do livre-arbítrio do indivíduo que simplesmente "decide" proceder dessa forma, mas sim pelo modo como o atual jogo entre as relações de produção e as forças produtivas tecnológicas determina a necessidade de tal emissão. $\mathrm{O}$ e-mail que não é lido e respondido a tempo pode custar tanto a perda de uma oportunidade vital de ascensão profissional, quanto o acirramento da frustração da pessoa que lamenta e se ressente diante da demora da resposta. Frente à intensificação cada vez maior da aceleração tecnológica, as reconfiguraçôes das esferas do trabalho, e do suposto tempo livre, parecem adquirir sentido só quando são convergidas em imagens, por meio da ação das TIC, as quais, de acordo com Huws (2009, p. 38), se revelam "tanto tecnologias da produção quanto do consumo. Logo, é provável que a posse ou a carência destas crie uma nova grande ruptura no contexto de populações inteiras. 'Divisão digital' é o termo da moda para essa ruptura”. 
Paradoxalmente, enquanto tal divisão digital se afirma e tem como consequência a exclusão de populações inteiras que se encontram marginalizadas em relação ao domínio das TIC, as novas e velhas mídias se convergem e aproximam, de uma maneira inaudita, as esferas do trabalho e do tempo livre. Não por acaso, a palavra convergência também compartilha outro significado na sociedade da denominada revolução microeletrônica, ou seja, no nosso "olho do furacão". Jenkis (2008) chega a afirmar que hoje impera a "cultura de convergência", compreendida pelas mudanças das e nas "nossas práticas socioculturais em função das influências da tecnologia, da economia e da convergência da velha e nova mídia”. Ele acentua que a convergência midiática acarreta mais do que uma simples visão de mudança tecnológica, quando altera as relações entre as tecnologias e indústrias, frequentemente contraditórias. A primeira, relacionada ao poder e controle, refere-se à "tendência de grandes empresas de mídia a ameaçar a democracia pela sua concentração de propriedade, dando a menos pessoas uma maior capacidade de empurrar e ampliar o seu conteúdo limitado para as massas" (idem, ibid.). A segunda tendência, relacionada à democracia e participação social, aduz a possibilidade das novas tecnologias permitirem acesso, criação e distribuição das mídias de maneiras muito mais diversificadas como, por exemplo, em forma de redes sociais ou comunidades, blogs, twitter etc.

A observação de Jenkis sobre tal ambiguidade quanto aos empregos das novas tecnologias lembra a constatação de Marcuse (1999, p. 101) de que a técnica, como mediação histórica que é, "impede o desenvolvimento individual apenas quando está presa a um aparato social que perpetua a escassez, e esse mesmo aparato liberou forças que podem aniquilar a forma histórica particular em que a técnica é utilizada”. Ou seja, a defesa intransigente daqueles que condenam a técnica, em decorrência de seus possíveis efeitos deletérios, reafirma a existência da burocracia autoritária, que poderia ser questionada por meio das potencialidades emancipatórias da própria técnica. $\mathrm{O}$ mesmo raciocínio foi também destacado por Günther Anders, no seu livro $A$ antiguidade do homem, principalmente quando elaborou o conceito de vergonha prometeica. Tal como no mito de Prometeu, que furtou o fogo dos deuses e o entregou ao seres humanos, que não mais precisariam dos deuses em função do domínio de tal técnica, os indivíduos contemporâneos também se vêem às voltas com a potência de suas maravilhas tecnológicas e se envergonham diante de tal magnificência, pois 
a fragilidade da carne se torna evidente (Anders, 2002). Porém, ao invés da vergonha - como sentimento moral que é - proporcionar condições para o exercício da autocrítica do modo como os objetos se tornam sujeitos, enquanto seus produtores se tornam objetos facilmente descartáveis e substituíveis por outros, ela faz com que os indivíduos queiram cada vez mais se assemelhar maquinalmente a esses produtos, ao passo que tais produtos como que se humanizam.

No momento em que há a "transformação da cognição em insumo produtivo", a reificação do trabalhador, no contexto do capitalismo transnacional, "se configura como uma tentativa de humanizar a máquina desde o projeto de uma inteligência artificial que deve ser constantemente alimentada de dados por um 'trabalho informacional'" (Wolf, 2009, p. 102). Ora, refletir sobre tais contradiçóes apontadas por Marcuse, Jenkis, Anders e Wolf significa necessariamente enfrentálas. E há tal enfrentamento quando se reflete sobre a sociedade na qual a tecnologia não mais pode ser definida como uma somatória de novas técnicas operacionais, mas sim como uma espécie de modus vivendi, como um processo social que determina as reconfigurações identitárias dos indivíduos.

No Documento-Referência da CONAE, há uma série de pertinentes considerações sobre a importância da ampliação da chamada educação tecnológica, sobretudo no incentivo à presença dos laboratórios de informática nas escolas, pesquisas on-line e intercâmbios científicos e tecnológicos, nacional e internacional, entre instituiçôes de ensino, pesquisa e extensão. Contudo, nota-se a ausência de uma reflexão mais desenvolvida sobre a forma como as novas TIC determinam os rumos dos atuais processos de ensino e aprendizagem. A ênfase sobre os aspectos técnicos envolvidos no uso dos instrumentais listados no documento não pode ser absolutizada a ponto de ofuscar a necessária discussão sobre o papel da tecnologia como processo social que reconfigura as características identitárias dos agentes educacionais.

A legítima defesa da garantia de utilização das tecnologias e conteúdos multimidiáticos, por parte dos profissionais da educação (CONAE, 2010), não pode subordinar a reflexão crítica da forma como tais tecnologias também mediatizam as novas tonalidades dos processos de ensino e aprendizagem. Seguindo essa linha de raciocínio, serão feitas ponderações sobre o modo como a educação a distância (EaD) é abordada nesse documento, cujo objetivo central é o de subsidiar a elaboração do novo 
PNE 2011-2020, na forma do estabelecimento de diretrizes e estratégias de ação.

\section{A EaD e a formação do PNE 2011-2020}

$\mathrm{Na}$ leitura do Documento-Referência da CONAE, nota-se a presença da discussão sobre os critérios de desenvolvimento de uma política de formação e valorização dos profissionais da educação. Faz parte da implantação de tal política promover espaços para a reflexão crítica sobre as diferentes linguagens midiáticas, que vicejam das mais variadas formas e que engendram alterações substanciais tanto em relação às características dos processos formativos dos profissionais da educação, quanto ao desenvolvimento dos processos de ensino e aprendizagem (CONAE, 2010).

Ou seja, nota-se a presença da preocupação quanto à influência que as TIC exercem sobre os agentes educacionais, assim como a relevância da garantia de que tais agentes possam utilizar as chamadas tecnologias e conteúdos multimidiáticos, a ponto de se poder ampliar cada vez mais a denominada educação tecnológica (CONAE, 2010). Contudo, quais seriam as características dessa educação? Certamente, apesar de ser determinante, o mero acesso ao uso da internet, por meio de uma maior quantidade de computadores disponíveis aos professores e alunos, não implica, por si só, a garantia de que o acesso aos conteúdos informativos se converta verdadeiramente em formação educacional.

Em tempos em que textos, números e sons convergem em imagens absolutamente sedutoras, a ponto dos alunos pouco se interessarem pelos conteúdos que não são transmitidos pelos aparelhos de data show nas salas de aula, não há como desconsiderar o fato de que também as capacidades psicocognitivas se alteram, notadamente o desenvolvimento da memória. A história do pensamento pedagógico é prenhe de polêmicas sobre a análise do papel da memória no desenvolvimento do processo de ensino-aprendizagem. Nas obras dos autores identificados como partícipes da chamada pedagogia tradicional, tal como Johann F. Herbart, a memória sempre ocupou um posto de destaque quanto ao progresso do processo educacional/formativo, embora, em algumas situaçôes-limite, flertasse com posturas autoritárias que exigiam que os conteúdos fossem decorados à custa do sofrimento dos alunos. $\mathrm{O}$ próprio Herbart 
expressou a intenção de vincular o aprendizado dos conteúdos memorizados com a internalização da necessidade de obediência ao mestre da seguinte forma: “'um dia me agradecerás!', diz o educador ao rapaz lavado em lágrimas” (2003, p. 43).

Já na chamada pedagogia moderna, fruto de reformas pedagógicas, enfatizou-se, tal como no exemplo dado por John Dewey, a necessidade de que a memorização considerasse os interesses do corpo discente, pois assim os conteúdos teriam mais chance de ser efetivamente assimilados. Contudo, também tais práticas não se alijariam da produção de situações-limite, pois se poderia sobrevalorizar os interesses dos alunos em detrimento dos conteúdos aprendidos, a ponto da própria criança determinar a quantidade e a qualidade do ensino (Dewey, 1978).

De todo modo, é interessante observar como a discussão sobre a relação entre memória e práticas pedagógicas ocorre na sociedade da tecnologia digital, sobretudo pela convergência cada vez mais abrangente entre a computação e as indústrias de telecomunicações (Briggs \& Burke, 2006). A convergência dos textos, números e sons em imagens que se consubstanciam em arrebatadores estímulos audiovisuais promove, paradoxalmente, a dispersão da concentração, uma vez que as informações conectadas são substituídas por outras, por meio do ritmo alucinante das trocas de links. A pausa necessária para que o conhecimento possa ser, digamos, digerido, rarifica-se cada vez mais, na medida em que a concentração é pulverizada para, logo em seguida, se reconfigurar momentaneamente, até que outro link seja acessado. É nesse sentido que a qualidade desse link, dessa ligação, tem que ser discutida pedagogicamente pelos agentes educacionais. Histórica e filosoficamente, o conceito de memória foi associado ao afeto empregado na reflexão do que se aprendera. Aprender algo de forma verdadeira implicava apreender afetivamente esse algo. Steiner (2005, p. 46-47), ao comentar o significado etimológico da palavra decorar, assevera que,

Num sentido mais simples, o que sabemos de cor (no coração) amadurecerá e se desdobrará dentro de nós. O texto memorizado interage com nossa existência temporal, modificando nossas experiências, sendo dialeticamente modificado por elas. Quanto mais fortes forem os músculos da memória, mais bem guardada estará a integridade do nosso eu.

Esse alerta de Steiner sobre a necessidade de se fortalecer os músculos da memória, como garantia da integridade do eu, contrasta com 
O Plano Nacional de Educação e as tecnologias da informação e comunicação...

a flacidez mnemônica que é intensamente recrudescida por meio da atual forma de utilização das TIC. No Documento-Referência da CONAE (2010), especificamente no eixo 2, referente à qualidade da educação, gestão democrática e avaliação, lê-se que "Não há como educar para a autonomia, criatividade e autoconfiança, numa instituição moldada no conteudismo, na memorização e na fragmentação do conhecimento" (p. 56). De fato, a autonomia, criatividade e autoconfiança nunca puderam ser desenvolvidas por meio de práticas pedagógicas que associavam a memorização de conteúdos fragmentados e alheios aos interesses dos alunos. É nesse sentido que a palavra "decorar" se distancia cada vez mais do seu sentido afetivo original, ao mesmo tempo em que se aproxima do seu sentido atual concernente à decoração maçante a improdutiva. Porém, essa afirmação presente no documento não pode ser historicamente descontextualizada, sobretudo na atual sociedade, cuja convergência das forças produtivas, notadamente as tecnológicas, determina o modo como a fragmentação do conhecimento se nutre do contínuo arrefecimento da memorização. A atual flacidez mnemônica está visceralmente coadunada ao modo como a transmissão e recepção dos conhecimentos são fragmentadas. Ou seja, quaisquer considerações sobre a relação entre autonomia, criatividade, autoconfiança, conteudismo, memorização e fragmentação do conhecimento não podem se apartar tanto da maneira como tais relações se desenvolvem na chamada sociedade da revolução microeletrônica, quanto das consequências que essas relações produzirão nas práticas pedagógicas dos agentes educacionais.

Um dos principais, senão o principal, destaque presente no Documento-Referência sobre a relação entre as TIC e a educação se refere à educação a distância (EaD). De acordo com dados da Secretaria de Educação a Distância do MEC, o programa Universidade Aberta do Brasil (UAB) teria papel decisivo para viabilizar a formação universitária de $30 \%$ dos estudantes brasileiros até 2011. Se considerarmos que, no nosso país, apenas $10 \%$ dos brasileiros com idade entre 18 a 24 anos têm acesso aos cursos de graduação nas universidades, então nos tornamos cientes tanto da pretensão quanto da vultuosidade do programa da UAB.

Evidentemente, a vultuosidade de tal pretensão não passou despercebida pelos educadores e educadoras, cujas vozes se fizeram presentes no Documento-Referência da CONAE. É interessante analisar a forma de abordagem da questão: EaD presente no documento. Com 
efeito, no eixo 4, referente à formação e valorização dos/das profissionais da educação, lê-se que tal processo educacional/formativo deve

(...) extinguir, ainda, todas as políticas aligeiradas de formação por parte de "empresas", por apresentarem conteúdos desvinculados dos interesses da educação pública, bem como superar políticas de formação que têm como diretriz o parâmetro operacional do mercado e visam um novo tecnicismo, separando concepção e execução na prática educacional. (CONAE, 2010, p. 80)

A ironia da aspas da palavra empresas certamente alude à crítica de que tais políticas de formação, cujo aligeiramento é de grande interesse das chamadas indústrias de diplomas, revigoram o tecnicismo educacional em nosso país, em tonalidades mais afeitas à sociedade do capitalismo transnacional ultratecnológico. Diferentemente do conluio observado entre o governo militar brasileiro e os empresariados nacional e internacional, durante o período da ditadura e da consolidação das bases do capitalismo monopolista, a possibilidade de existência do novo tecnicismo se esteiaria na instrumentalização tecnológica a serviço dos interesses de tais "empresas", numa escala de progressão geométrica quando comparada àquela de progressão aritmética do governo militar. Nesse sentido, a difusão on-line de conhecimentos, proporcionada pelas atuais TIC, ao invés de possibilitar maior e mais rápido acesso a tais conhecimentos e, dessa forma, estimular o desenvolvimento do processo educacional/formativo, contribuiria para a revitalização daquilo que Adorno (1996) denominou semiformação, ou seja, a conquista do espírito pelo caráter de fetiche da mercadoria como decorrência da atual forma on-line de industrialização dos produtos "culturais". Seguindo essa linha de raciocínio, esse novo tecnicismo produziria a danificação da dimensão subjetiva, por meio da reprodução do conhecimento fragmentado e estereotipado, ao dirimir a consciência das mediaçôes históricas responsáveis pela produção do próprio conhecimento. A adesão ao imediato, em detrimento do historicamente mediado, ocorreria por meio do consumo contínuo das informações fragmentadas, convergidas em estímulos audiovisuais.

Talvez essa seja a principal preocupação quanto à denominada EaD, a ponto de se observar a defesa de que a formação inicial deverá se dar de forma presencial, admitindo-se a seguinte exceção: “(...) a formação inicial pode, de forma excepcional, ocorrer na modalidade EaD 
para os/as profissionais da educação em exercício, onde não existam cursos presenciais, cuja oferta deve ser desenvolvida sob rígida regulamentação, acompanhamento e avaliação" (CONAE, 2010, p. 83; grifo do original).

De fato, a qualidade dos cursos de formação inicial oferecidos na modalidade EaD se tornou objeto de pesquisas que investigam as formas de produção e recepção dos conhecimentos, a relação entre professores, alunos e tutores dos cursos, as possíveis formas de avaliação a distância, a presença ou não das condições infraestruturais necessárias para a transmissão dos conhecimentos nas universidades e para formação dos polos de recepção, entre outros aspectos. É verdade que, como bem destaca o Documento-Referência da CONAE, há várias instituiçōes, localizadas no interior dos estados e nas capitais, que fomentam a proliferação de seus cursos de formação inicial de EaD sem o "devido acompanhamento pedagógico, sem a aprovação do MEC e sem compromisso com a formação de qualidade dos estudantes, visando apenas o lucro das entidades e a distribuição de diplomas em curto prazo" (CONAE, 2010, p. 84).

O pressuposto básico do Documento-Referência é o de que não há como desconsiderar as diferenças qualitativas existentes entre processo de ensino e aprendizagem realizado presencialmente e a distância. Se, já nos processos formativos presenciais, há várias dificuldades de acompanhamento e avaliação dos problemas de toda ordem que possam surgir, o que dizer de tais dificuldades ocorridas em processos a distância? Evidentemente, a comunicação primária, que se objetiva nas relações presenciais, deveria ser estimulada pelos recursos tecnológicos que propiciam a chamada comunicação secundária, efetuada a distância. $\mathrm{Ou}$ seja, a comunicação primária não deve ser subordinada à secundária, mas sim ser reforçada por esta. Mas uma questão que poderia surgir de tal comparação entre as comunicações primária e secundária de tais processos educacionais seria a seguinte: Nos processos formativos efetuados a distância, não poderia haver condições para que esses mesmos recursos tecnológicos fossem utilizados para aproximar, inclusive presencialmente, os agentes educacionais?

Já há dados na literatura que permitem reconhecer o sucesso dos procedimentos educacionais a distância que incentivaram tais aproximaçôes. De acordo com Belloni (1999, p. 47), não só a frequência, como também os níveis de comprometimento dos estudantes de cursos a distância se fundamentam na "exigência de retorno imediato da informação, o que 
explica a receptividade a mídias interativas (telefone, e-mail); do desejo de encontrar outros estudantes, o que permite comparar dificuldades e discutir sobre a qualidade dos cursos; da necessidade de encontrar pessoalmente os tutores".

Não se pode afirmar que as relações presenciais entre os agentes educacionais garantam por si só a ocorrência do elo pedagógico fundamentado no respeito e na aproximação efetiva entre os professores e alunos, haja vista o fato de que muitos professores se ausentam presencialmente no transcorrer de suas aulas, principalmente quando desqualificam seus alunos e se julgam os únicos portadores da verdade; ou, então, dos alunos, cujo descaso de sua presença física denuncia a distância de seus interesses em relação ao conteúdo das matérias. Do mesmo modo, não é possível afirmar, categoricamente, que os professores que ministram suas aulas por meio do uso de recursos tecnológicos nunca irão desenvolver tal elo, justamente porque se econtram fisicamente afastados de seus alunos. No uso dos recursos proporcionados pelas TIC, corre-se o risco de se referendar uma dupla reificação: eles podem ser tanto sedutoramente considerados como os substitutos dos professores, numa espécie de revitalização da vergonha prometeica anteriormente mencionada, quanto podem ser tecnofobicamente identificados como fatores impeditivos para o desenvolvimento do processo educacional/formativo, exatamente porque estimulam a produção e difusão do conhecimento fragmentado. Atento para a possibilidade de existência dessa dupla reificação, o próprio Documento-Referência da CONAE (2010, p. 81) enfatiza a relevância de se assegurar

(...) o desenvolvimento de competências e habilidades para o uso das tecnologias de informação e comunicação (TIC) na formação inicial e continuada dos/das profissionais da educação, na perspectiva de transformação da prática pedagógica e da ampliação do capital cultural dos/das professores/as e estudantes.

Como se pode observar, os dizeres contidos no próprio documento reforçam a importância do domínio das TIC por parte dos agentes educacinais, pois há a anuência de que a elaboração e difusão do conhecimento não podem ser separadas do uso e do controle de tais tecnologias. O reconhecimento da importância do controle das TIC para a ampliação do capital cultural dos agentes educacionais se refere tanto à formação inicial, quanto à formação continuada. E se há a aceitação dessas tecnologias, de tal modo que não é possível acusar a presença de uma 
postura tecnofóbica em tal documento, como se pode compreender a defesa de que a EaD, bem com todos os recursos tecnológicos envolvidos em suas práticas pedagógicas devam se reportar à formação continuada e não à inicial, com a exceção dos lugares onde não existam cursos presenciais?

A resposta para essa questão poderia enveredar para duas justificativas: 1) dever-se-ia coadunar as práticas educacionais a distância com a formação continuada, uma vez que se trataria de um espécie de complemento formativo importante para o desenvolvimento do capital cultural dos agentes educacionais. Justamente por se tratar de um complemento, ela não poderia se associada aos processos formativos/educacionais iniciais, os quais demandariam a presença efetiva dos professores; 2) se houvesse o incentivo da associação entre a EaD e os cursos de formação inicial de forma ampla e irrestrita, então, se legitimariam a produção e a reprodução desenfreada da chamada indústria de diplomas.

Ambas as justificativas apresentam consistência na elaboração e na defesa de seus argumentos. Por um lado, não se pode desprezar as diferenças existentes entres as formaçóes inicial e continuada, as quais dizem respeito aos distintos níveis de maturidade e de domínio de conteúdos pedagógicos, ao menos supostamente. Por outro lado, em virtude das conhecidas dificuldades de gerência e de controle do Ministério da Educação, seria praticamente impossível evitar a proliferação da indústria de diplomas e dos consequentes prejuízos educacionais/formativos.

Porém, a veracidade de tais argumentos não são suficientes para que se possa esquivar de outras duas ponderações: 1) o próprio Documento-Refência admite que, se fosse possível relacionar a formação continuada por meio da EaD com "uma política integrada a um conjunto de ações formativas presenciais", haveria a possibilidade de "democratização e acesso a novos espaços e ações de formação" (CONAE, 2010, p. 84). Então, por que esse mesmo esforço não poderia ser empregado para o desenvolvimento das práticas pedagógicas dos cursos de formação inicial, desde que fossem analisadas e respeitadas as particularidades teóricas e práticas de cada curso para saber se poderiam ou não ser ministrados a distância?; 2) se, historicamente, a fabricação de diplomas já pode ser observada em nosso país bem antes da existência das atuais TIC, esse fato por si só eximiria o MEC de se esforçar para acompanhar e controlar os cursos de formação inicial a distância, uma vez 
que, reconhecida a inevitabilidade do processo de industrialização de diplomas, seria mais adequado colocar abstáculos à existência de praticamente todos esses cursos?

$\mathrm{Na}$ verdade, o processo de alfabetização digital (Kellner \& Share, 2008) - que implica, principalmente, a capacidade de selecionar os conteúdos apreendidos por meio das tecnologias digitais e tensioná-los entre si, de modo a gerar aprendizado efetivo - se transforma numa questão decisiva, ao impingir o enfrentamento dessas duas questões colocadas anteriormente. Não basta, pois, ter o conhecimento de como operar um computador e acessar a infinidade de conhecimentos por meio da internet, se falta a necessária capacidade de relacionar os conteúdos entre si, engendrando novas questões que impulsionam o indivíduo a conhecer criticamente mais. Mas, para que isso aconteça, tem que haver uma relação de continuidade e de temporalidade entre tais conteúdos, de tal maneira que as informações recebidas possam servir de lastro para o desenvolvimento da formação cultural. Não por acaso, tal como foi observado anteriormente, no próprio documento CONAE nota-se a defesa da importância do domínio das TIC não só em relação à formação continuada, como também à formação inicial.

Torna-se imperativo refletir sobre o modo pelo qual a educação incorpora as tecnologias, especialmente no que diz respeito à formação de professores e à introdução das tecnologias midiáticas na escola. A transposição das TIC para as práticas educacionais deve ser feita por meio de uma análise minuciosa das suas vantagens e limites, permitindo assim a crítica de uma possível incorporação instrumental e reificada dessas tecnologias. A alfabetização digital não é suficiente e, sequer, prioritária na formação do professor, quando isolada dos conceitos epistemológicos, filosóficos e sociológicos que subjazem às ciências da educação e às políticas públicas, conceitos estes fundamentais para a elaboração de um projeto pedagógico que verse sobre os processos de EaD, sejam eles de formação inicial ou continuada. Assim, é a educação que não só fundamenta, como também ressignifica o emprego das TIC em suas práticas. Ao se conceber o processo de alfabetização digital dessa forma, inevitavelmente se defende a centralidade do papel do professor, uma figura que não pode ser substituída pela do tutor nos processos de EaD, e que foi muito bem destacada nas linhas do Documento-Referência da seguinte forma: 
Tal compreensão retrata o papel da EaD sob a ótica da formação de qualidade social, que não prescinde do acompanhamento efetivo, nem de momentos presenciais de aprendizagem coletiva. Nesse sentido, deve-se garantir e regulamentar um número proporcionalmente adequado de estudantes por professorl a e por carga horária remunerada, a fim de assegurar o acompanhamento individualizado. (CONAE, 2010, p. 85; grifos nossos)

É dessa forma que o uso das TIC pode engendrar aprendizado efetivo, uma vez que não se esquiva da elaboração de um projeto pedagógico que, tal como no caso da EaD, impulsiona o desenvolvimento do processo educacional/formativo. Contra a utilização desenfreada e, na maior parte das vezes, afeita aos interesses da industrialização on-line de diplomas, lê-se no próprio Documento-Referência que é possível a criação de políticas públicas que defendem outro processo de EaD. Ou seja, um processo que não compactue com a razão instrumental hegemônica dos atuais cursos a distância que assolam e deterioram a educação de nosso país; os mesmos cursos cuja reprodução desmesurada fornece a falsa impressão de que contribuem para a democratização do ensino nas mais variadas instâncias.

\section{Conclusão}

Quais são os limites das ações humanas em relação à tecnologia produzida por essas mesmas ações? A constatação de que vivemos numa época em que a tecnologia ocupa uma posição-chave, a ponto de se metamorfosear numa espécie de modus vivendi, expõe o seguinte dilema que, como pessoas tecnologizadas que somos, não podemos evitar: até que ponto exercemos uma relação patológica com os produtos tecnológicos que engendramos, os mesmos produtos que parecem adquirir uma áurea identitária que lhes confere a condição de sujeito, enquanto nos transformamos em objetos? É no atual contexto social que, cada vez mais,

As pessoas inclinam-se a considerar a técnica como algo em si, como um fim em si mesmo, como uma força com vida própria. Mas com isso se esquecem que ela se trata do braço prolongado do homem. Os meios, e a tecnologia é a essência dos meios para a autopreservação da espécie humana, são fetichizados porque os fins - uma existência digna do ser humano - são encobertos e apartados do consciente humano. (Adorno, 1971, p. 100) 
A reflexão crítica sobre esse processo de fetichização tecnológica precisa ser fomentada de todas as formas. Na leitura do Documento-Referência da CONAE, percebe-se, em alguns momentos, a presença de uma linha argumentativa que menciona a necessidade do incentivo a essa reflexão crítica por parte dos profissionais da educação, embora se possa observar também uma postura um tanto quanto periférica sobre a discussão da relação entre a educação e a tecnologia, haja vista o fato de que tal relação não adquiriu a condição de eixo temático do documento.

Numa sociedade em que a tecnologia ocupa posição decisiva, a ponto de ressignificar as configurações das relaçôes humanas em todas as suas esferas, a discussão dos eixos direcionadores das futuras políticas públicas de educação não pode abster-se de uma análise mais apurada sobre o modo como as atuais relações de produção determinam transformações cada vez mais aceleradas na esfera da superestrutura e, portanto, nas instituições que as compóem, principalmente as escolares. Dessa forma, a relação entre educação, memorização e fragmentação do conhecimento, tal como destacada no Documento-Referência da CONAE, tem que ser compreendida num contexto em que o atual uso instrumentalizado das TIC impele a fragmentação do conhecimento, na medida em que a capacidade de concentração é pulverizada. E, na mesma proporção em que a fragmentação do conhecimento é promovida pela atual indústria cultural, as concepçóes pedagógicas críticas precisam incentivar a permanência da memória, inclusive por meio do uso das TIC, como condição para que os conteúdos continuem historicamente presentes, de tal modo que haja o tempo necessário para que eles sejam tensionados entre si e auxiliem na produção de uma "refinada capacidade de se pensar conceitualmente e em sequência”, tal como destacou Postman (2005, p. 113). Assim, há uma chance de que as informaçôes que esteiam os currículos das formaçôes inicial e continuada possam ser elaboradas a ponto de se transformarem em conhecimentos relevantes para o processo educacional/formativo. Já outra questão central presente no documento da CONAE se refere à relação entre as TIC e a denominada educação a distância.

Contra a proliferação da indústria de diplomas, observa-se, no documento da CONAE, o alerta da possibilidade de revitalização do tecnicismo pedagógico, cujas influências em nosso país são notadas desde a época do regime militar. Torna-se, portanto, decisiva a promoção de um debate nacional para que sejam elaborados projetos pedagógicos relativos 
a uma educação a distância compromissada, por exemplo, com um número proporcionalmente adequado de estudantes e de professores, tal como foi destacado naquele documento. E que, sobretudo, considere as especificidades teóricas e práticas de cada curso que possa ser realizado a distância, seja ele de formação inicial ou continuada. Talvez assim se torne viável um projeto de educação a distância para cursos de formação continuada e inicial que não sejam comprometidos com uma educação que tenha como principal escopo a compra e venda de diplomas. Ainda que de forma incipiente, nota-se no documento indícios de uma proposta pedagógica que utiliza os recursos das TIC para promover a alfabetização digital crítica da pretensa neutralidade tecnológica. São, pois, os fundamentos epistemológicos, filosóficos e sociológicos, subjacentes às políticas públicas educacionais, que determinam a forma de utilização dos recursos das TIC junto aos currículos das formações inicial e continuada e não o contrário (Pino, 2008 e 2010). A construção do Plano Nacional de Educação não pode desconsiderar a predominância de tais fundamentos na elaboração de suas diretrizes e estratégias de ação, principalmente quando estas se referem ao liame estabelecido entre as novas TIC e o processo educacional/formativo.

Portanto, as políticas públicas educacionais devem incorporar a necessidade imperiosa de discussão sobre o modo como tais recursos tecnológicos ressignificam as características das teorias e práticas pedagógicas e dos processos de construção das identidades dos agentes educacionais. As ressignificaçóes de tais teorias, práticas e identidades se inserem no contexto da cultura da convergência, anteriormente destacada por Jenkins (2008), que pode engendrar tanto um maior controle das grandes empresas de mídia sobre as TIC, quanto acessos e participações mais amplas e democráticas no uso de recursos das redes sociais ou comunidades, blogs, twitter e outros meios de comunicação.

Nesse sentido, tal como advertem Burbules e Callister (2008), torna-se fundamental questionar como, quem e com que finalidades as novas tecnologias são utilizadas. A projeção de tais questóes, que remetem o uso das TIC para além do dado imediato, permite relembrar o mito de Prometeu: se, na mitologia grega, Prometeu é aquele que pensa antecipadamente (Galimberti, 2006), faz-se ainda mais necessária a crítica que pressente a utilização fetichizada da tecnologia. Se tal crítica for feita, talvez a vergonha que sentimos diante do poder dos aparatos tecnológicos nos impulsione para a autorreflexão sobre o modo 
como continuamente nos aferramos à condição de objetos, e não de sujeitos de nossas ações educativas, as quais são mediadas, cada vez mais, pelas novas tecnologias de informação e comunicação.

Recebido e aprovado em agosto de 2010.

\section{Referências}

ADORNO, T.W. Erziehung nach Auschwitz. In: Adorno, T.W. Erziehung zur Mündigkeit. Frankfurt am Main: Suhrkamp, 1971.

ADORNO, T.W. Teoria da semicultura. Educação \& Sociedade, Campinas, v. 17, n. 56, p. 388-412, dez. 1996.

ANDERS, G. Die Antiquiertheit des Menschen I. München: C.H. Beck, 2002.

BELLONI, M.L. Educação a distância. Campinas: Autores Associados, 1999.

BENJAMIN, W. Obras escolhidas: magia e técnica, arte e política. São Paulo: Brasiliense, 1985.

BRASIL. Ministério da Educação. Universidade Aberta do Brasil. Disponível em: <http://www.uab.mec.gov.br/cursopiloto.php>. Acesso em: 8 ago. 2006.

BRIGGS, A.; BURKE, P. Uma história social da midia: de Gutenberg à internet. Rio de Janeiro: Zahar, 2006.

BURBULES, N.C; CALLISTER, T.A. Educación: riesgos y promesas de las nuevas tecnologías de la información. Buenos Aires: Granica, 2008.

CASTELS, M. A sociedade em rede. São Paulo: Paz \& Terra, 2007.

CONFERÊNCIA NACIONAL DE EDUCAÇÃO (CONAE), 2010, Brasília, DF. Construindo o Sistema Nacional Articulado de Educação: o Plano Nacional de Educação, diretrizes e estratégias; Documento Final. Brasília, DF: MEC, 2010. Disponível em: <http://Conae.mec.gov.br/ images/stories/pdf/pdf/doc_base_documento_final.pdf>. Acesso em: 7 jun. 2010. 
O Plano Nacional de Educação e as tecnologias da informação e comunicação...

DEWEY, J. Vida e educação. Rio de Janeiro: Melhoramentos, 1978.

GALIMBERTI, U. Psique e techne: o homem na idade da técnica. São Paulo: Paulus, 2006.

HERBART, J.F. Pedagogia geral. Lisboa: Fundação Calouste Gulbenkian, 2003.

HUWS, U. A construção de um ciberproletariado?: trabalho virtual num mundo real. In: Antunes, R.; Braga, R. (Org.). Infoproletários: degradação real do trabalho virtual. São Paulo: Boitempo, 2009. p. 37-59.

JENKINS, H. Cultura da convergência. São Paulo: Aleph, 2008.

KELLNER, D.; SHARE, J. Educação para a leitura crítica da mídia, democracia radical e reconstrução da educação. Educação \& Sociedade, Campinas, v. 29, n. 104, p. 687-717, out. 2008.

MARCUSE, H. Tecnologia, guerra e fascismo. São Paulo: UNESP, 1999.

PINO, I.R. As TIC na formação a distância: reflexões contemporâneas. Retratos da Escola, Brasília, DF, v. 2, n. 2-3, p. 109-120, jan./dez. 2008.

PINO, I.R. A educação básica e superior, as tecnologias de informação $e$ comunicação e os conteúdos multimidiáticos. Disponível em: <http:// www.cedes.unicamp.br/textos_conae.htm>. Acesso em: 4 ago. 2010.

POSTMAN, N. O desaparecimento da infância. Rio de Janeiro: Graphia, 2005.

STEINER, G. Liçôes dos mestres. Rio de Janeiro: Record, 2005.

TÜRCKE, C. Erregte Gesellschaft: philosophie der sensation. München: C.H. Beck, 2002.

WOLF, S. O trabalho informacional e a reificação da informação sob os novos paradigmas organizacionais. In: Antunes, R.; BRAGA, R. (Org.). Infoproletários: degradação real do trabalho virtual. São Paulo: Boitempo, 2009. p. 89-113. 